Article

\title{
Dynamic Analysis of China's Imported Raw Milk Powder Consumption
}

\author{
Yuting Wang ${ }^{1}$, Lei Wang ${ }^{1}$ and Zhemin $\mathrm{Li}^{1,2, *}$ \\ 1 Agricultural Information Institute, Chinese Academy of Agricultural Sciences, Beijing 100081, China; \\ wangyuting@caas.cn (Y.W.); lei_wanghn@163.com (L.W.) \\ 2 Graduate School, Chinese Academy of Agricultural Sciences, Beijing 100081, China \\ * Correspondence: lizhemin@caas.cn; Tel.: +86-010-82106345
}

Received: 10 December 2019; Accepted: 2 February 2020; Published: 19 February 2020

\begin{abstract}
Raw milk powder is one of most important raw materials for dairy processing and manufacturing. In the past decade, the rapid growth of imported raw milk powder (IMP) consumption has brought about significant impacts on China's social economy. For more in-depth analysis of such impacts, this study develops a comprehensive IMP consumption model for China covering 2007-2015 based on the input-output analysis method from the perspective of material metabolism. In detail, material flows and consumption analysis are employed to reveal the direct and indirect IMP consumption and supply of various sectors. Using an innovative hierarchy analysis and network utility analysis, the internal structure of the IMP consumption system and consumption relationships between different sectors are identified. Due to the increasing intensive production activities between the manufacture and processing of the dairy products sector and others, its downstream sectors have grown rapidly and the consumption relationships with others are mostly mutualism. The surge in IMP has caused dramatic changes in consumption relationships, which has the greatest impact on the service sectors, followed by manufacturing sectors. The rapid increase in IMP consumption has put great pressure on the supply and consumption of intermediate products of many sectors.
\end{abstract}

Keywords: powdered milk; input-output analysis; consumption relationships analysis; hierarchy analysis; China

\section{Introduction}

As the world's largest importer of dairy products, China imported 0.72 million tons of raw milk powder in 2017, accounting for about $29.0 \%$ of China's total international trade in dairy products [1]. Raw milk powder is one of most important raw materials in the manufacture and processing of dairy products, and is widely used in the production of formula milk powder, yogurt, reduced milk, milk beverages, and functional foods [2]. The increasing import of raw milk powder has greatly enriched the dairy market in China, and has also supplied more and more diversified raw materials for dairy manufacturing and processing enterprises [3]. However, this surge means that China's dairy consumption is increasingly dependent on large dairy exporting countries, such as New Zealand and Australia, which has triggered varying impacts on China's dairy market and China's industrial structure [4-6]. Therefore, it is indispensable to investigate the impacts of imported raw milk powder (IMP) consumption on different economic sectors in China [7,8].

Many scholars have done a lot of research on the impact of the surge of IMP on China's social and economy and the development of China's dairy industry [9]. However, most of these studies are at the stage of surface data interpretation and phenomena elaboration $[2,10]$, and there is limited deep analysis from the perspective of the socio-economic system and material metabolism [11-13]. 
Environmentally-extended input-output analysis (EEIOA) [14,15] provides a way to amplify the invisible complex material flows from the perspective of urban metabolism through the economic flow characteristics of the input-output tables $[16,17]$. Based on this method, it is possible to describe the complex material flows caused by commodities trade among various economic sectors and to reveal the internal structure of a regional metabolism system [18,19]. Based on input-output analysis, ecological network analysis (ENA) $[20,21]$ is proposed as a useful method to investigate a system's function and internal relationships between different sectors [22,23]. In recent years, EEIOA and ENA have been employed in many areas to explore the consumption and metabolism characteristics of substances such as food [24], water [25], energy [26], waste [27], etc. [28-30]. However, previous studies have focused on environmental and ecological elements [19,31], and there has been little research on the consumption of dairy products in this way $[25,32]$.

In order to fill this gap, this paper establishes an imported raw milk powder (IMP) consumption model for China from 2007 to 2015 based on EEIOA and ENA methods to evaluate the impacts of rapidly increasing consumption of IMP on different economic sectors in China. More specifically, material flow and consumption analysis methods are applied to reveal the direct and indirect IMP flows, as well as the indirect IMP consumption of various sectors, thus key sectors of this IMP system can be identified. Moreover, using an innovative hierarchy analysis (HA) and network utility analysis (NUA) methods, the internal structure and IMP consumption relationships within its hierarchy are discussed. It is expected that this paper could conduct a more in-depth analysis of the impact of the rapid increase in IMP consumption on China's socio-economic system.

The rest of the paper is structured as follows: Section 2 describes an overview of China's import of raw milk powder, Section 3 shows the methodology and data applied in this study, Section 4 analyses the detailed results, Section 5 discusses the results, and Section 6 summaries the conclusions.

\section{Overview of China's Imports of Raw Milk Powder}

As shown in Figure 1, since 2000, the consumption of dairy products in China has continued to increase, and the import volume has been relatively stable, leading to the rapid development of China's dairy industry. In detail, from 2000 to 2007, the domestic dairy production increased from 827.4 tons to 35.25 million tons, while the dairy product imports were stable at around 0.3 million tons. However, after suffering from the 2008 "melamine" quality and safety incident, Chinese people lost trust in domestic dairy products. Moreover, in April of the same year, the signing and implementation of the Free Trade Agreement Between the Government of the People's Republic of China and the Government of New Zealand meant that China's tariffs on imports of dairy products from New Zealand would decrease year by year (they fell to zero in 2019). Since then, the total imports of dairy products increased from 0.39 million tons to 2.47 million tons during 2008-2017, with an average annual growth rate of $22.8 \%$. In 2017, China imported a total of 2.47 million tons of dairy products, including 0.72 million tons of raw milk powder $(29.0 \%), 0.70$ million tons of liquid milk (28.4\%), 0.53 million tons of whey $(21.4 \%)$, 0.30 million tons of infant formula milk powder $(12.0 \%), 0.11$ million tons of cheese $(4.4 \%), 0.09$ million tons of butter $(3.7 \%)$, and 0.03 million tons of refined milk (1.0\%). It is worth noting that the amount of IMP increased from 0.10 million tons to 0.72 million tons, with an average annual growth rate of $22.8 \%$. From the perspective of the country of origin of imported milk powder, China's IMP is mainly from New Zealand. In 2017, China imported 0.55 million (76.6\%) tons of raw milk powder from New Zealand, 0.09 million tons (11.9\%) from the European Union, 0.05 million tons (6.4\%) from Australia, and 0.03 million tons (4.7\%) from the United States. More data information is presented in Supporting Information Tables S1-S3. 


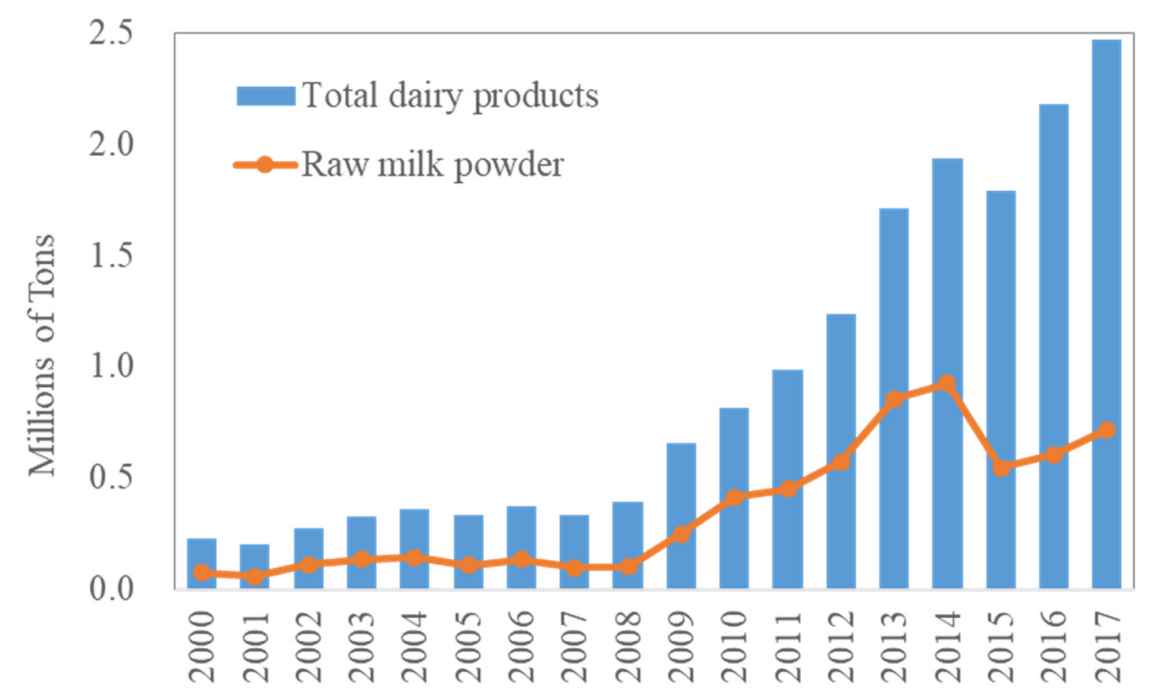

Figure 1. China's imports of total dairy products and raw milk powder from 2000 to 2017.

It is obvious that IMP has always played an important role in the Chinese dairy industry chain. Therefore, the increase in IMP has brought about a significant impact on China's social and economic system. As a raw material for the dairy manufacturing and processing industries, this low-cost IMP (including whole milk powder and skimmed milk powder) has made a significant contribution to the prosperity of this industry. On the other hand, the competition between IMP and the domestic fresh milk products has intensified, causing a serious blow to the domestic husbandry. China's Ministry of Agriculture and Rural Areas announced that in the past decade, $80 \%$ of the increase in China's dairy consumption market has been squeezed by the imported products, and the domestic production have hardly increased, forcing a large number of Chinese cattle farmers to lose their jobs.

Chinese government is very concerned about the rapid decline in the self-sufficiency rate of dairy products due to the sharp increase in imports. On June 11, 2018, the General Office of the State Council issued the Opinions on Promoting the Revitalization of Dairy Industry to Ensure the Quality and Safety of Dairy Products [33]. It is pointed out that by 2020, the dairy industry should be significantly improved, and the milk source rate should be greater than $70 \%$; by 2025 , the overall level of China's dairy industry should reach the world's first rank.

\section{Methodology}

\subsection{Modeling Framework}

Input-output analysis is used to describe the complex material flows caused by commodities trade among various economic sectors and to reveal the internal structure of a regional metabolism system [21]. Based on the Leontief and Ghosh framework [14,15,34], a comprehensive model of the imported raw milk powder consumption was established from the perspective of regional material metabolism [25,35]. In this model, the raw milk powder consumed in China imported from other countries is the initial input of the system.

For an economic system, the total output of sector $i$ is equal to the sum of its intermediate consumption and final demand [36]:

$$
x_{i}=z_{i 1}+z_{i 2}+\ldots+z_{i j}+\ldots z_{i n}+y_{i}=\sum_{j=1}^{n} z_{i j}+y_{i}
$$

Where $n=18$ indicates that there are 18 economic sectors in this system, $x_{i}$ is the total output of sector $i, z_{i j}$ stands for the intermediate sales by sector $i$ to sector $j$, and $f_{i}$ represents the final demand of sector $i[25,37]$. 
Based on production-based accounting, the concept of direct consumption intensity was then introduced to account for the IMP consumption for unitary output, as expressed by Equation (2) [38]. Thus, embodied intensity and enabled intensity are defined as follows [30]:

$$
\begin{gathered}
\varepsilon^{d}{ }_{i}=\frac{c_{i}}{x_{i}} \\
\varepsilon=\varepsilon^{\mathbf{d}}(\mathbf{I}-\mathbf{A})^{-1} \\
\boldsymbol{\mu}=(\mathbf{I}-\mathbf{B})^{-1}\left(\varepsilon^{\mathrm{d}}\right)^{\prime}
\end{gathered}
$$

where $\mathbf{C}=\left[c_{j}\right]_{1 \times n}$ is the initial input vector, $\varepsilon^{d}{ }_{i}$ denotes the direct consumption intensity of sector $i, \mathbf{I}$ is the identity matrix, $(\mathbf{I}-\mathbf{A})^{-1}$ and $(\mathbf{I}-\mathbf{B})^{-1}$ are the Leontief and Ghosh inverse matrix, respectively [15], $\varepsilon$ is the embodied IMP consumption intensity vector, and $\mu$ denotes the enabled IMP consumption intensity vector.

Using the embodied intensity, the monetary intermediate flow matrix $\mathbf{Z}=\left[z_{i j}\right]_{n \times n}$ can be transformed into material intermediate flow matrix $\mathbf{F}=\left[f_{i j}\right]_{n \times n}$.

$$
\mathbf{F}=\operatorname{diag}(\varepsilon) \cdot \mathbf{Z}
$$

where $\operatorname{diag}(\varepsilon)$ represents the diagonal matrix composed of $\varepsilon_{i}, f_{i j}$ stands for the IMP flow from sector $i$ to sector $j$ directly (i.e., sector $j$ consumes the intermediate IMP-related products supplied by sector i) $[17,29]$. Thus, $F_{j}=\sum_{i=1}^{n} f_{i j}$ stands for the indirect consumption of sector $j$, and $F_{i}=\sum_{j=1}^{n} f_{i j}$ is the indirect supply of sector $i$. Therefore, the total consumption $T_{j}$ that flows into sector $j$ from other sectors can be defined by Equation (6):

$$
T_{j}=F_{j}+c_{j}
$$

\subsection{Hierarchy Analysis}

In the IMP consumption system, there are two types of linkages between each sector and other components of the system due to the complex intermediate material flows [15]. The first one is backward linkage (BL), which is applied to describe the linkage between sector $i$ and its upstream sectors. The other is forward linkage (FL), which is employed to reflect the linkage between sector $i$ and its downstream sectors. Equations (7) and (8) provide the calculation formula for BL and FL [17]. From the perspective of supply and demand relationships, $B L_{i}$ reflects the dependence degree of sector $i$ on the supply of its upstream sectors, while $F L_{i}$ shows the dependence degree of sector $i$ on the demand of its downstream sectors. Based on these two linkages, hierarchical analysis of the IMP consumption system can be implemented.

$$
\begin{gathered}
B L_{i}=\frac{\varepsilon_{i}}{\frac{1}{n}\left(\sum_{i=1}^{n} \varepsilon_{i}\right)} \\
F L_{i}=\frac{\mu_{i}}{\frac{1}{n}\left(\sum_{i=1}^{n} \mu_{i}\right)}
\end{gathered}
$$

\subsection{Network Utility Analysis (NUA)}

NUA is developed in order to access the mutual consumption relationships between various sectors of the IMP consumption system $[16,25]$. The direct utility matrix $\mathbf{D}=\left[d_{i j}\right]$ reflects that only the initial flows are involved. $\mathbf{U}=\left[u_{i j}\right]$ is the integral utility matrix that represents the overall utility, including both direct and indirect effects originated from all possible pathways between sector $i$ and $j$. Equations (9) and (10) show their calculation method: 


$$
\begin{gathered}
d_{i j}=\frac{\left(f_{i j}-f_{j i}\right)}{T_{j}} \\
\mathbf{U}=\left[u_{i j}\right]=\mathbf{D}^{0}+\mathbf{D}^{1}+\mathbf{D}^{2}+\ldots+\mathbf{D}^{k}+\ldots=(\mathbf{I}-\mathbf{D})^{-1} .
\end{gathered}
$$

Thus, sign $\mathbf{U}$ denotes the symbolic function matrix of $\mathbf{U}$. For pairwise sectors, $(+,+)$ stands for a mutualism relationship, $(-,-)$ stands for competition, $(+,-)$ and $(-,+)$ stand for exploitation. $(0,0)$ stands for neutrality [21].

At a systematic point, the synergism index $(S I)$ and network mutualism index $(N M)$ were employed to evaluate fitness and symbiosis of the system [25,39]. If $S I>0$ and $N M>1$, then the system displays mutualism and synergism [40,41].

$$
\begin{gathered}
S I=\sum_{i=1}^{n} \sum_{j=1}^{n} u_{i j} \\
N M=\frac{\operatorname{sign} U(+)}{\operatorname{sign} U(-)}
\end{gathered}
$$

where $\operatorname{sign} U(+)$ and $\operatorname{sign} U(-)$ represent the number of +1 and -1 in signU, respectively.

\subsection{Data}

The basic data of this model are from two parts: the direct IMP consumption in China and the monetary input-output tables (MIOTs) in 2007, 2012, and 2015. The direct IMP consumption as the initial input comes from the United Nations Comtrade Database [1]. MIOTs are obtained from the Development Research Center of The State Council of China [42]. In particular, in order to better understand the impact on relevant sectors, the final input-output tables have been aggregated and disaggregated into 18 sectors according to the National Standard for the Classification of National Economy Industries of China jointly issued by the General Administration of Quality Supervision, Inspection and Quarantine of China, and the China National Standardization Administration and also the characteristics of China's socio-economic system, as listed in Table 1. Among them, S4 (Manufacture and processing of dairy products) was the initial input sector for this research. More basic data information is presented in Supporting Information.

Table 1. Sector Definition.

\begin{tabular}{ccc}
\hline Industry & Number & Sector \\
\hline A & S1 & Husbandry \\
M (Mining) & S2 & Farming, forestry, animal, fisheries, and water conservation \\
Mining
\end{tabular}




\section{Results}

\subsection{Material Flows and Consumption Analysis}

Figure 2 shows the indirect IMP consumption and supply of various sectors from 2007 to 2015. Overall, from 2007 to 2015, the total indirect IMP consumption (or supply) increased from $0.054 \mathrm{Mt}$ in 2007 to $0.539 \mathrm{Mt}$ in 2015. The indirect consumption (or supply) increased by 8.98 times, while the direct IMP consumption (or supply) increased by 4.56 times (as shown in Section 2), which indicates that the internal structure of the IMP consumption system has changed and it is meaningful to further analyze IMP consumption and the consumption relationships between different sectors.
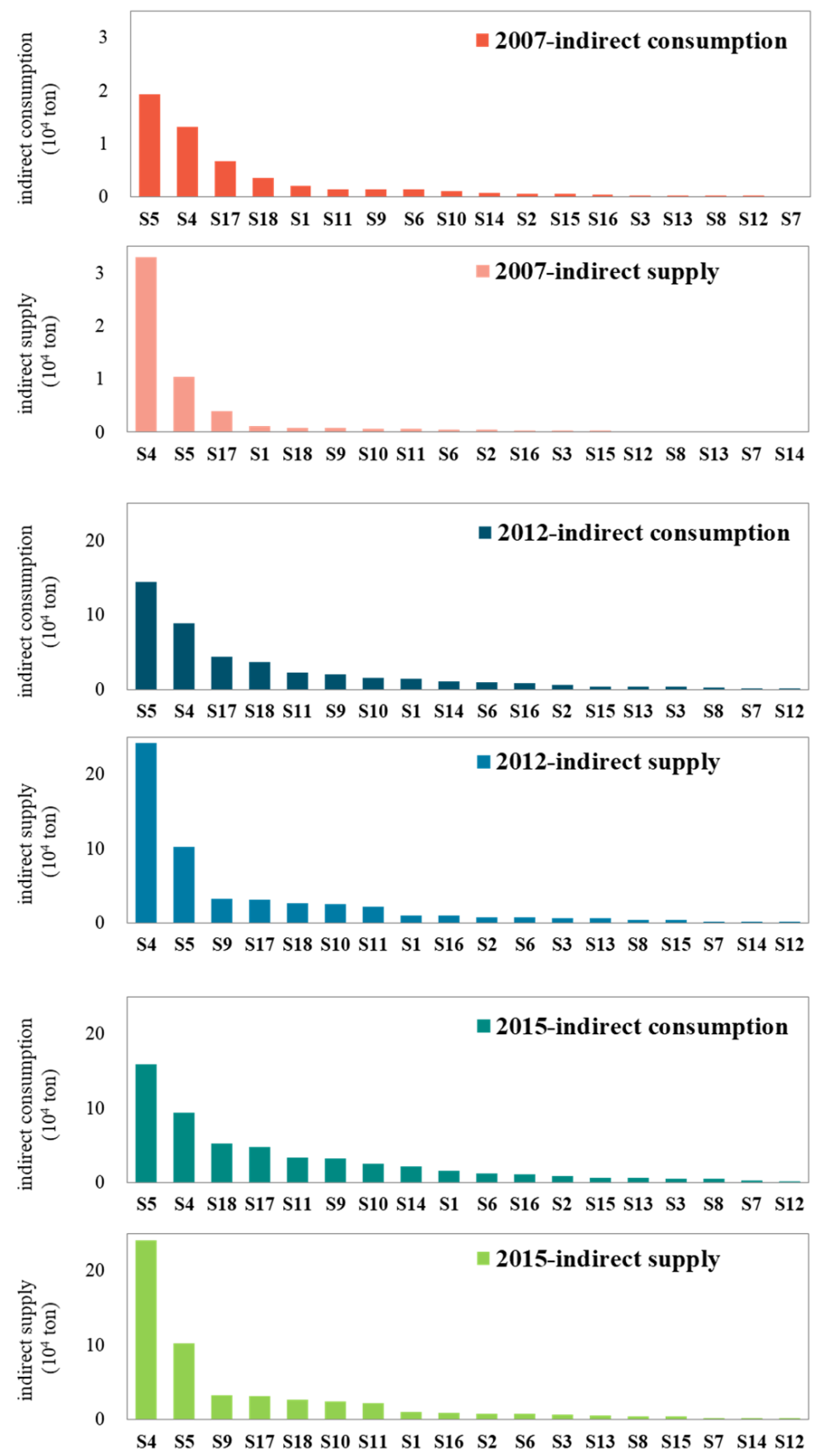

Figure 2. The indirect IMP consumption and supply of sectors in 2007, 2012 and 2015. Full data supporting this graph are listed in Tables S4-S6. The sectors in the abscissa axis are sorted in descending order of value. 
In order to further investigate the material flows among different sectors, Figure 3 shows the variation of direct IMP flows among sectors within the IMP consumption system from 2007 to 2015. For any sector in chord diagrams, in a clockwise direction, the chords that connects one sector to other sectors represents the direct IMP flows that the sector provides to others. In a counterclockwise direction, the chords that connect other sectors to the sector indicates that this sector consumes the direct IMP flows supplied by other sectors. Each sector has a specific color, and the color of a chord is displayed by the supply sector of the flow. For example, the yellow chords that connects S4 to S17 stand for the direct IMP flows supplied by S3 and consumed by S17.

Combing the results shown in Figures 2 and 3, we can deeply investigate the IMP flows and consumption relationships between various sectors so as to reveal the changes of internal structure of the IMP consumption system behind the rapid growth of direct IMP consumption. In general, from the sector-level perspective, the indirect IMP consumption and supply of sectors in each year varies significantly in Figure 2. From 2007 to 2015, as the largest indirect consumer, S5 (manufacture and processing of agricultural by-products, tobacco) uses lots of intermediate IMP-related products supplied by other sectors (shown in Figure 3), such as S4 (manufacture and processing of dairy products), S1 (Husbandry), and S2 (Farming, forestry, animal, fisheries, and water conservation), implying that although S5 (manufacture and processing of agricultural by-products, tobacco) does not directly consume the direct IMP input, many indirect material flows are passed to it due to the intensive production activities with other sectors. As a direct consumer, S4 (manufacture and processing of dairy products) also has a large indirect consumption. S4 (manufacture and processing of dairy products) is the major indirect supplier that provides intermediate commodities to S5 (manufacture and processing of agricultural by-products, tobacco), S17 (accommodation and catering), S18 (other service industries), and itself, reflecting that the production activities between S4 (manufacture and processing of dairy products) and these sectors are more intensive. S17 (accommodation and catering) consumes a large number of direct IMP flows originating from S4 (manufacture and processing of dairy products) and S5 (manufacture and processing of agricultural by-products, tobacco), and provides many IMP flows to other sectors, namely, advanced manufacturing (S9-S12), energy and materials transformation (S13), construction (S14), and other services (S15-S16 and S18).

(a) $\mathbf{2 0 0 7}$

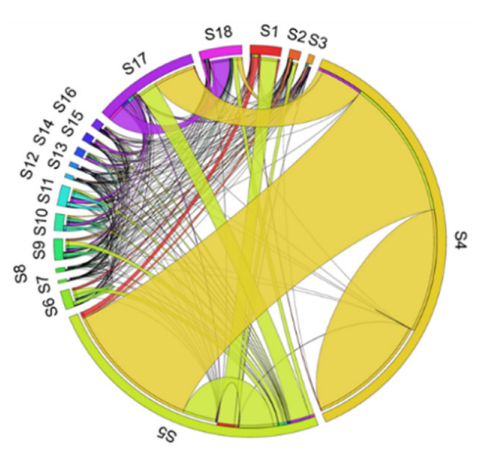

(b) 2012

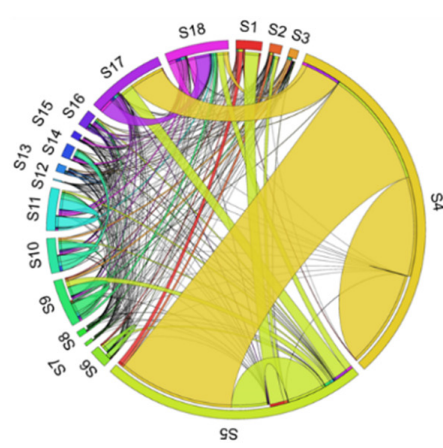

(c) 2015

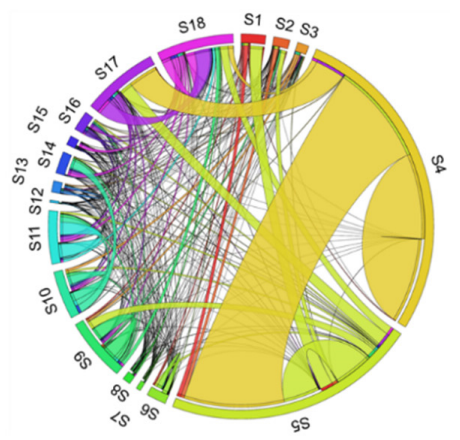

Figure 3. The intersectoral direct IMP flows over 2007-2015. Full data supporting this graph are listed in Tables S4-S6.

Further dynamic analysis finds that from 2007 to 2015, the proportion of S4's (manufacture and processing of dairy products) indirect supply in the system is getting smaller and smaller (in Figure 3), and the situation of S1 (Husbandry), S5 (manufacture and processing of agricultural by-products, tobacco), and S17 (accommodation and catering) is basically the same. At the same time, the proportion of $\mathrm{S}^{\prime}$ 's (manufacture and processing of dairy products) intermediate consumption in the system is also falling, while other sectors, such as $\mathrm{S} 9$ (manufacture of raw chemical materials and chemical products), S10 (manufacture of metal and non-metallic products), S11 (manufacture of equipment and instrument), and S14 (construction) are becoming more and more important as intermediate commodities consumers 
in the system. In other words, the proportion of S4 (manufacture and processing of dairy products) in the IMP consumption network is gradually decreasing, and the proportion of the manufacturing sectors is gradually increasing.

\subsection{Hierarchy Analysis}

Figure 4 shows the hierarchy of the IMP consumption system based on the forward linkage and backward linkage in 2007, 2012, and 2015. Forward linkage reflects the linkage between a sector and its downstream sectors, which can be understand as the driving function of the sector on the development of the entire system. Therefore, for a well-developed metabolism system, the hierarchical map drawn by the forward linkage of various sectors should have an almost perfect pyramid shape (Note: The upstream industries are at the bottom and the downstream industries are at the top). In fact, the pyramids in Figure 4 (a1, b1, c1) are a bit irregular. From 2007 to 2015, the irregular shapes mainly result from the too-large driving function of $\mathrm{A}+\mathrm{M}$ (such as $\mathrm{S} 1$ (husbandry)) and $\mathrm{ET}+\mathrm{C}+\mathrm{S}$ (such as $\mathrm{S} 13$ (energy and materials transformation), S15 (wholesale and retail), and S16 (transportation, storage and post)), and the too-small driving function of AM (e.g., S10 (manufacture of metal and non-metallic products) and S11 (manufacture of equipment and instrument)). The forward linkage of S1 (husbandry) increases from 0.6316 to 0.7839 during 2007-2015, indicating that the driving force of S1 to the system is enhanced. The forward linkage of advanced manufacturing sectors all decrease, for example, S9 (manufacture of raw chemical materials and chemical products) is reduced by $27.16 \%$, resulting in their driving force more insufficient. Meanwhile, the change in the forward linkage of sectors in $\mathrm{S}$ (service) industry causes the pyramid's top layer deformity.
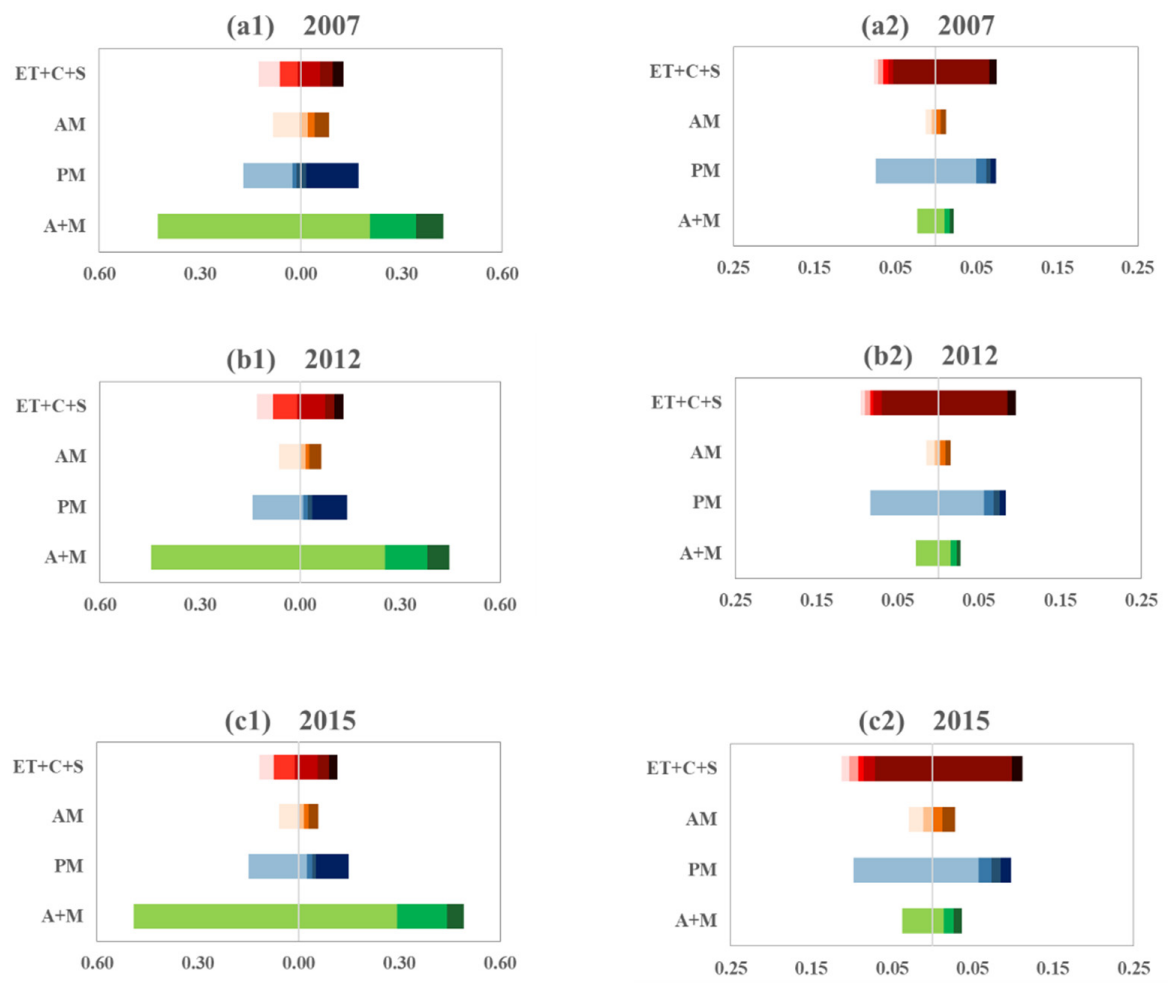

\begin{tabular}{|l|l|l|l|l|l|l|l|l|l|l|l|l|l|l|l|l|}
\hline \multicolumn{2}{|c|}{ A } & M & \multicolumn{5}{|c|}{ PM } & \multicolumn{5}{c|}{ AM } & ET & C & \multicolumn{3}{c|}{ S } \\
\hline S1 & S2 & S3 & S5 & S6 & S7 & S8 & S9 & S10 & S11 & S12 & S13 & S14 & S15 & S16 & S17 & S18 \\
\hline & & & & & & & & & & & & & & & & \\
\hline
\end{tabular}

Figure 4. Hierarchy analysis based on the forward linkage (a1, b1, c1, and backward linkage (a2, b2, c2,). Full data supporting this graph are listed in Table S7. 
Backward linkage stands for the linkage between a sector and its upstream sectors, which also denotes the pulling function of the sector to the development of the whole system. For a well-developed metabolism system, the hierarchical map drawn by sectoral backward linkage of should be an inverted pyramid shape. The inverted pyramid in Figure $4(\mathrm{a} 2, \mathrm{~b} 2, \mathrm{c} 2)$ is more irregular, mainly because AM pulls its upstream sectors insufficiently, whereas $\mathrm{PM}$ and $\mathrm{A}+\mathrm{M}$ pull other sectors too quickly. In particular, the backward linkage of S5 (manufacture and processing of agricultural by-products, tobacco) increases from 0.1250 to 0.1550 during 2007-2015, indicating that S5's demand for its upstream sectors is growing. More specifically, S5 consumes an increasing number of raw materials provided by S1 (husbandry) and S2 (farming, forestry, animal, fisheries, and water conservation) for its own production activities, but this consumption is too excessive to be support by the upstream industries, which lets S5 must rely heavily on external inputs, namely, imports. Moreover, the inverted pyramid of this system based on backward linkage becomes abnormally deformed, reflecting that S4's (manufacture and processing of dairy products) heavy dependence on imports has a serious impact on the sustainable development of the system.

\subsection{Consumption Relationships Analysis}

Figure 5 shows the interaction amongst sectors using block diagrams based on the integrated utility matrices. The warm color blocks stand for positive effects, while cold tone blocks represent negative effects. For example, in 2007, the color block of column S1 of row S5 is close to deep red, which means that S5 (manufacture and processing of agricultural by-products, tobacco) delivers a positive utility to S1 (husbandry). Figure 5 shows that the utilities of different sectors vary greatly. From 2007 to 2015, almost all utilities transmitted from S4 (manufacture and processing of dairy products) and S5 (manufacture and processing of agricultural by-products, tobacco) to other sectors are positive, and their values gradually decrease year by year. Moreover, S9 (manufacture of raw chemical materials and chemical products) and S17 (accommodation and catering) provide a lot of positive utilities for other sectors, while S3 (mining), S8 (manufacture of paper and paper products), S12 (other manufacturing), and S14 (construction) obtain more and more positive utilities.

To further analyze pairs of relationships and explore their dynamic trends, Figure 6 summarizes the IMP consumption relationships between pairs of sectors (i.e., mutualism, exploitation, competition and itself relationships, and itself relationships are excluded in the analysis of this section). In general, 18 sectors reveal a total of 153 pairs of mutual consumption relationships. Exploitation relationships account for a large proportion in this system, which is $64.71 \%, 71.24 \%$, and $71.24 \%$ in 2007,2012 , and 2015 , respectively. Meanwhile, there is $8.33 \%$ increase in the mutualism relationships and $40 \%$ decrease in competition relationship. In 2007, the consumption relationships between S4 (manufacture and processing of dairy products) and all sectors except S5 (manufacture and processing of agricultural by-products, tobacco) and S17 (accommodation and catering) are mutualism. This result indicates that when $S 4$ (manufacture and processing of dairy products) passes positive utilities to other sectors, it also obtains positive utilities, thus all sectors benefit from the relationships. Competitive relationships appear most frequently in S18 (other service industries), which reflects that the consumption demand of S18 puts stress on its upstream sectors for IMP related commodities supply.

Dynamic analysis of the evolution of consumption relationships finds that there are 32 pairs of relationship changes from 2007 to 2012. Especially, nine pairs of changed relationships are related to S18 (other service industries). Among them, seven pairs change from competition to exploitation (i.e., S18-S3, S18-S6, S18-S9, S18-S10, S18-S12, S18-S14, and S18-S15), a pair changes from mutualism to exploitation (i.e., S18-S5), and one change from exploitation to competition (i.e., S18-S7). The number of changed relationships in S12 (other manufacturing) is the second largest, of which 5 pairs change from competition to exploitation (i.e., S12-S9, S12-S15, S12-S16, S12-S17, and S12-S18), one change from mutualism to exploitation (i.e., S12-S5), and one change from exploitation to mutualism (i.e., S12-S11). During 2012-2015, there are only six pairs of consumption relationships changes. The relationships of S1-S15 and S13-S15 change from exploitation to competition and the relationship of S11-S13 changes 
from mutualism to exploitation. The relationships of S13-S9 and S13-S12 change from competition to exploitation and the relationship of S5-S7 changes from exploitation to mutualism.

(a) $\mathbf{2 0 0 7}$

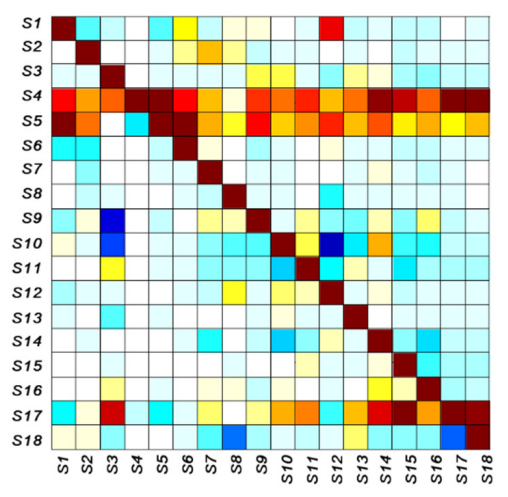

(c) 2015

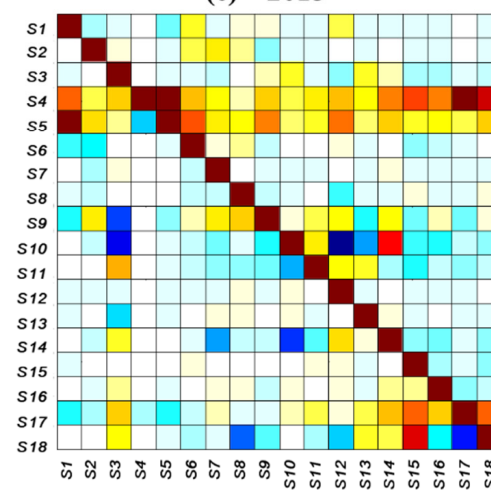

(b) 2012
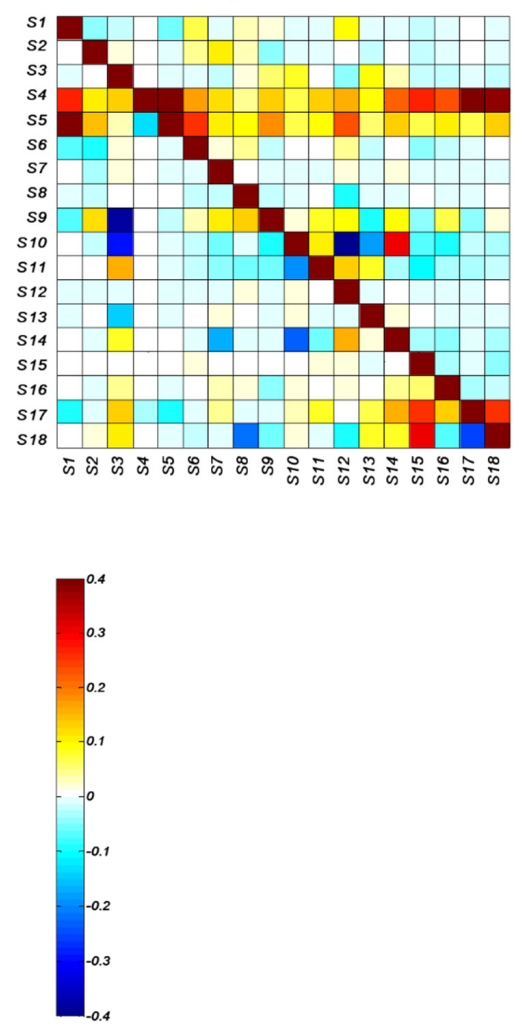

Figure 5. The integrated utility of 18 sectors in 2007, 2012, and 2015.

(a) 2007

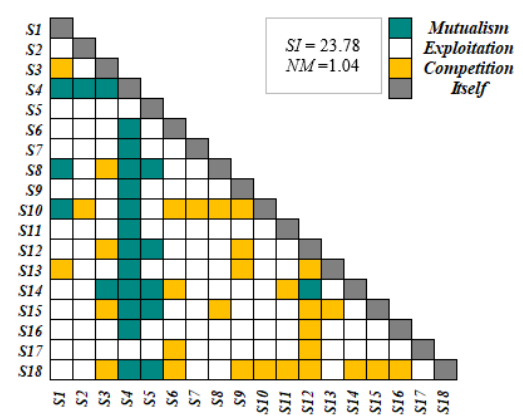

(c) 2015

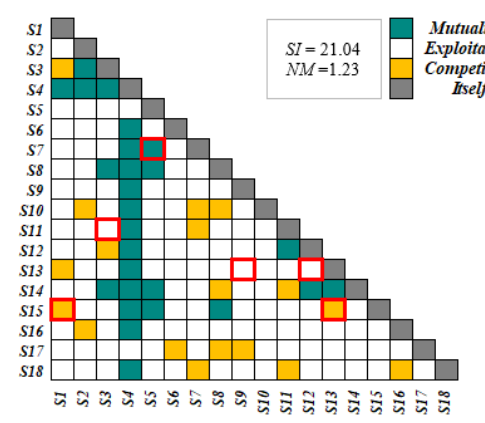

(b) 2012

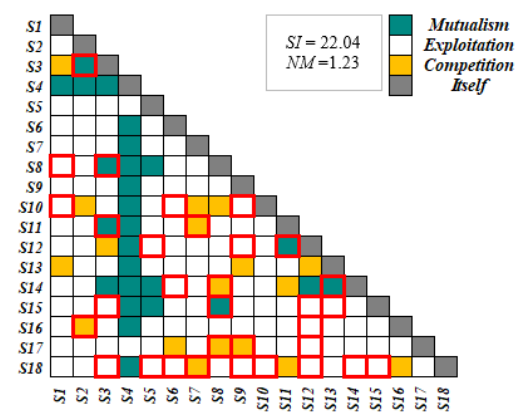

Figure 6. Consumption relationships between pairwise sectors. 
From the systemic perspective, during 2007-2015, the synergism indexes (SI) decrease from 23.78 to 21.04, implying that although it has a slight decrease, the performance of the system is still conducive to development (i.e., SI is greater than 0). Meanwhile, network mutualism indexes (NM) of the IMP consumption system are all higher than 1 and the values increase, indicating that the system has more positive utility relationships and displays mutualism and synergism.

\section{Discussions}

Before 2007, China's dairy consumption mainly depended on domestic production. With the implementation of the Free Trade Agreement Between the Government of the People's Republic of China and the Government of New Zealand in 2008, the share of imported dairy products in the Chinese market surged, especially the imported raw milk powder (IMP), which brought about nonnegligible impacts on China's social and economic system.

In fact, IMP consumption mainly relies on the "reconstitution-processing-sales" industrial chain. In detail, the "reconstruction" refers to the manufacturing process of reconstituted milk, which mainly relies on S4 (manufacture and processing of dairy products) to dissolve IMP and also relies on the advanced manufacturing industries S9-S12 to provide additives such as nutrients. The "processing" represents that after sterilization and ultra-high temperature treatment, reconstituted milk is again supply into some relevant primary manufacturing sectors S5-S8 as an intermediate product. With reprocessing, packaging, and other processes in these sectors, it is manufactured into yogurt, formula milk, sterilized milk, condensed milk, etc. The "sales" depends on the service sectors S15-S18. Meanwhile, these complex industrial production processes are inseparable from the supply of water and energy in S13 (Energy and materials transformation). Actually, people are the main body of the socio-economic system. The ultimate purpose of IMP's flow and consumption is actually to meet human needs (as a kind of food), so as to provide sufficient labor for each industry to serve the socio-economic system and eventually achieve sustainable development. From this perspective, the input of the IMP has a certain impact on all sectors in the entire socio-economic system. This study aims to develop a model to dynamically investigate the internal structure of China's IMP consumption system from a more scientific perspective and thus to evaluate the impacts of rapidly increasing consumption of IMP on various economic sectors and on the consumption relationships among sectors.

Material flows and consumption analysis indicate that with the continuous increase of the direct IMP consumption, the downstream sectors of S4 (manufacture and processing of dairy products) have been rapidly developed. The change of total indirect IMP consumption is much greater than that in direct IMP consumption, which implies the significant change in the internal structure of the IMP consumption system. The findings show that at the sectoral level, during 2007-2015, S4 (manufacture and processing of dairy products) inputs increased direct IMP to this system, while S5 (manufacture and processing of agricultural by-products, tobacco) serves as the largest indirect consumer. At the same time, S17 (accommodation and catering) consumes a large number of IMP-related intermediate commodities supplied by its upstream sectors and produces other intermediate goods to its downstream sectors along the IMP supply chains. Moreover, the indirect consumption and supply share of S4 (manufacture and processing of dairy products) is decreasing year by year, and the shares of the manufacturing sectors are gradually increasing. This reflects that IMP have gradually penetrated into the Chinese market, resulting in closer internal connections of the consumption system, and the materials exchange between sectors caused by the initial inputs of S4 (manufacture and processing of dairy products) has become more and more complicated.

Hierarchy analysis shows that from a supply-side perspective, the increasing IMP consumption makes the forward linkage of the lower-layer sectors of the metabolism hierarchy larger, but the surging supply of intermediate commodities to the service industries (e.g., S15-S18) makes its driving force to the system too large. From a demand-side perspective, the increasing IMP consumption enhances the backward linkage of sectors at the top of the consumption hierarchy but makes intermediate demand in primary manufacturing (i.e., S5-S8) and husbandry sector (i.e., S1) over-expanded, resulting in excessive 
pulling function at the lower layer of the metabolism hierarchy. For the advanced manufacturing sectors (i.e., S9-S12), its linkage analysis results show a significant shortage from both the supply-side and demand-side perspectives. It means that the surge in IMP's initial input has put tremendous pressure on the supply and consumption of intermediate goods in the advanced manufacturing sectors. That is to say, when a large amount of IMP is input, the related sectors has not made timely feedback and adjustments. Therefore, these sectors are the focus of the regulation of IMP consumption and supply structure in the future.

The results of consumption relationships analysis reveal that exploitation relationships predominate. Although the surge in IMP initial input from 2007 to 2012 made the consumption relationships among different sectors of the IMP consumption system undergo great changes, the system still has more positive utility relationships and displays mutualism and synergism. At the sectoral level, the majority consumption relationships between S4 (manufacture and processing of dairy products) and other sectors are mutualism in each year. In other words, the increasing IMP investment in S4 has made the dairy product manufacturing industry flourish, and the intensive production activities between industries have led to positive progress in the majority related industries. Meanwhile, the surge in IMP has caused a huge change in consumption relationships, which has the greatest impact on the service industries (e.g., S18), followed by the manufacturing sectors (e.g., S12).

Overall, due to the very low cost of IMP and the guiding role of import policies (China's tariff on IMP is gradually reduced), the share of IMP-related products in the Chinese market has gradually increased. While revitalizing the manufacture and processing of dairy products (i.e., S4), it has promoted competition in the primary manufacturing (i.e., S5-S8) and husbandry sector (i.e., S1) markets and also has positive effects on the development of the service sectors (i.e., S15-S18) through increasing intermediate products supply. For example, in order to cope with competition, husbandry sector needs to improve production technology and reduce costs, so it has promoted the development of domestic husbandry sector to some extent. At the same time, the increase in IMP puts pressure on China's husbandry and thus promotes the implementation of large-scale farming technologies, improves breeding levels and resource utilization, and also reduces the environmental burden caused by the breeding process, such as solid waste. However, the surge in IMP supply causes negative impacts on the stability and sustainability of the consumption system and breaks the original consumption mechanism, leading to huge changes in consumption relationships between various sectors. For example, some sectors find it difficult to provide timely feedback and adjust their supply and demand characteristics, hence requiring long-term adjustments to adapt.

\section{Conclusions}

In this paper, a comprehensive model of the imported raw milk powder (IMP) consumption has been developed and applied to China from the perspective of material metabolism to explore the impact of the rapid increase in IMP consumption on China's socio-economic system. Under the IMP consumption framework of this study, material flows and consumption analysis have been employed to reveal the direct and indirect IMP consumption and supply of various sectors. Based on forward linkage and backward linkage, hierarchy analysis is conducted to investigate the internal structure of the consumption system. Furthermore, combined with network utility analysis approach, the consumption relationships between different sectors are identified.

It was found that the change of total indirect IMP consumption is much greater than that in direct IMP consumption, which implies significant changes in the internal structure of the IMP consumption system. With the continuous increase of the direct IMP consumption, the production activities between S4 (manufacture and processing of dairy products) and other sectors are more intensive, thus S4's downstream sectors have been rapidly developed, especially in S5 (manufacture and processing of agricultural by-products, tobacco) and S17 (accommodation and catering). Meanwhile, the rapid increase in IMP has put a lot of pressure on the supply and consumption of intermediate products of many sectors, resulting in the irregular pyramid structure and irregular inverted pyramid structure, 
respectively. In addition, exploitation relationships account for a large proportion in this system each year. During 2007-2015, the surge in IMP has caused huge changes in consumption relationships between sectors, with the greatest impact on the service sectors (e.g., S18), followed by manufacturing (e.g., S12).

Future research should address some limitations in this paper. In addition, the authors will try other related methods (such as SAM for multiplier analysis) in the future to this study. Bilateral trade between regions (EEBT) models for China and New Zealand will be developed to better understand the embodied socio-economic and environmental impacts of New Zealand's Dairy Imports.

Supplementary Materials: The following are available online at http://www.mdpi.com/2071-1050/12/4/1542/s1, Table S1: China's imports of total dairy products and raw milk powder, Table S2: China's imports of various dairy products in 2017, Table S3: China's raw milk powder imports from various countries in 2017, Table S4: The intersectoral flows of the imported raw milk powder consumption system based on $f_{i j}$ in 2007, Table S5: The intersectoral flows of the imported raw milk powder consumption system based on $f_{i j}$ in 2012, Table S6: S6 The intersectoral flows of the imported raw milk powder consumption system based on $f_{i j}$ in 2015, Table S7: The forward linkage and backward linkage of different sectors in the imported raw milk powder consumption system during 2007-2015.

Author Contributions: Conceptualization, L.W.; methodology, L.W.; validation, Y.W. and Z.L.; formal analysis, L.W.; investigation, Y.W.; data curation, Y.W.; Writing-original draft, Y.W. and L.W.; Writing-review \& editing, Y.W. and Z.L.; visualization, L.W.; supervision, Z.L.; funding acquisition, Y.W. and Z.L. All authors have read and agreed to the published version of the manuscript.

Funding: This research was funded by the Innovation Project of Chinese Academy of Agricultural Sciences, grant number CAAS-ASTIP-2019-AII-02, Funding for Outstanding Talents of the Ministry of Agriculture of the People's Republic of China and the Outstanding Talents of Chinese Academy of Agricultural Sciences.

Conflicts of Interest: The authors declare no conflict of interest.

\section{References}

1. United Nations. United Nations Comtrade Database-International Trade Statistics [WWW Document]. 2016. Available online: https://comtrade.un:data/ (accessed on 9 October 2018).

2. Wei, Y.; Zhu, J. Source of Import, Technical Content and Technological Progress: Based on the Analysis about Influence of Dairy Import of China on the Technological Progress of Domestic Dairy Progressing Industy. Int. Econ. Trade Res. 2017, 33, 74-86. [CrossRef]

3. Liu, C.; Han, L.; Zhang, Y. International Comparison and Development Suggestions of China's Dairy Industry Competitiveness. Chin. Rural Econ. 2018, 403, 132-146.

4. Lin, J.; Pan, D.; Davis, S.J.; Zhang, Q.; He, K.; Wang, C.; Streets, D.G.; Wuebbles, D.J.; Guan, D. China's international trade and air pollution in the United States. Proc. Natl. Acad. Sci. USA 2014, 111, 1736-1741. [CrossRef]

5. Meng, J.; Liu, J.; Yi, K.; Yang, H.; Guan, D.; Liu, Z.; Zhang, J.; Ou, J.; Dorling, S.; Mi, Z.; et al. Origin and Radiative Forcing of Black Carbon Aerosol: Production and Consumption Perspectives. Environ. Sci. Technol. 2018, 52, 6380-6389. [CrossRef]

6. Mi, Z.; Meng, J.; Guan, D.; Shan, Y.; Song, M.; Wei, Y.M.; Liu, Z.; Hubacek, K. Chinese $\mathrm{CO}_{2}$ emission flows have reversed since the global financial crisis. Nat. Commun. 2017, 8, 1712. [CrossRef]

7. Khonpikul, S.; Jakrawatana, N.; Sangkaew, P.; Gheewala, S.H. Resource use and improvement strategy analysis of the livestock and feed production supply chain in Thailand. Int. J. Life Cycle Assess. 2017, 22, 1692-1704. [CrossRef]

8. Tang, Z.; Liu, W.; Gong, P. The measurement of the spatial effects of Chinese regional carbon emissions caused by exports. J. Geogr. Sci. 2015, 25, 1328-1342. [CrossRef]

9. Dong, X.; Liu, Z. Influence of Free Trade Agreements on Imports of Milk Powder in China. Food Nutr. China 2011, 17, 38-41.

10. Kibiego, M.B.; Lagat, J.K.; Bebe, B.O. Assessing the Economic Efficiency of Dairy Production Systems in Uasin Gishu County, Kenya. J. Econ. Sustain. Dev. 2015, 6, 146-154.

11. Li, S.; Zhang, Y.; Yang, Z.; Liu, H.; Zhang, J. Ecological relationship analysis of the urban metabolic system of Beijing, China. Environ. Pollut. 2012, 170, 169-176. [CrossRef] 
12. Tao, F.; Xu, Z.; Duncan, A.A.; Xia, X.; Wu, X.; Li, J. Driving forces of energy embodied in China-EU manufacturing trade from 1995 to 2011. Resour. Conserv. Recycl. 2018, 136, 324-334. [CrossRef]

13. Tukker, A.; Goldbohm, R.A.; De Koning, A.; Verheijden, M.; Kleijn, R.; Wolf, O.; Pérez-Domínguez, I.; Rueda-Cantuche, J.M. Environmental impacts of changes to healthier diets in EuroHpe. Ecol. Econ. 2011, 70, 1776-1788. [CrossRef]

14. Leontief, W.W. Input-Output Economics. Sci. Am. 1951, 185, 15-21. [CrossRef]

15. Miller, R.E.; Blair, P.D. Input-Output Analysis: Foundations and Extensions, 2nd ed.; The United States of America by Cambridge University Press: New York, NY, USA, 2009. [CrossRef]

16. Yang, X.; Zhang, W.; Fan, J.; Yu, J.; Zhao, H. Transfers of embodied PM2.5emissions from and to the North China region based on a multiregional input-output model. Environ. Pollut. 2018, 235, 381-393. [CrossRef]

17. Zhang, H.; Chen, L.; Tong, Y.; Zhang, W.; Yang, W.; Liu, M.; Liu, L.; Wang, H.; Wang, X. Impacts of supply and consumption structure on the mercury emission in China: An input-output analysis based assessment. J. Clean. Prod. 2018, 170, 96-107. [CrossRef]

18. Lin, B.; Long, H. Emissions reduction in China's chemical industry-Based on LMDI. Renew. Sustain. Energy Rev. 2016, 53, 1348-1355. [CrossRef]

19. Su, B.; Ang, B.W.; Li, Y. Input-output and structural decomposition analysis of Singapore's carbon emissions. Energy Policy 2017, 105, 484-492. [CrossRef]

20. Yang, Z.; Zhang, Y.; Li, S.; Liu, H.; Zheng, H.; Zhang, J.; Su, M.; Liu, G. Characterizing urban metabolic systems with an ecological hierarchy method, Beijing, China. Landsc. Urban Plan. 2014, 121, 19-33. [CrossRef]

21. Zhang, Y.; Zheng, H.; Fath, B.D.; Liu, H.; Yang, Z.; Liu, G.; Su, M. Ecological network analysis of an urban metabolic system based on input-output tables: Model development and case study for Beijing. Sci. Total Environ. 2014, 468-469, 642-653. [CrossRef]

22. Fath, B.D. Network mutualism: Positive community-level relations in ecosystems. Ecol. Model. 2007, 208, 56-67. [CrossRef]

23. Fath, B.D.; Patten, B.C. Network synergism: Emergence of positive relations in ecological systems. Ecol. Model. 1998, 107, 127-143. [CrossRef]

24. Lin, B.; Lei, X. Carbon emissions reduction in China's food industry. Energy Policy 2015, 86, 483-492. [CrossRef]

25. Fang, D.; Chen, B. Ecological network analysis for a virtual water network. Environ. Sci. Technol. 2015, 49, 6722-6730. [CrossRef]

26. Zhang, Y.; Yang, Z.; Fath, B.D.; Li, S. Ecological network analysis of an urban energy metabolic system: Model development, and a case study of four Chinese cities. Ecol. Model. 2010, 221, 1865-1879. [CrossRef]

27. Court, C.D.; Munday, M.; Roberts, A.; Turner, K. Can hazardous waste supply chain "hotspots" be identified using an input-output framework? Eur. J. Oper. Res. 2015, 241, 177-187. [CrossRef]

28. Chen, L.; Liang, S.; Zhang, Y.; Liu, M.; Meng, J.; Zhang, H.; Tang, X.; Li, Y.; Tong, Y.; Zhang, W.; et al. Atmospheric Mercury Outflow from China and Interprovincial Trade. Environ. Sci. Technol. 2018, 52, 13792-13800. [CrossRef]

29. Chen, L.; Meng, J.; Liang, S.; Zhang, H.; Zhang, W.; Liu, M.; Tong, Y.; Wang, H.; Wang, W.; Wang, X.; et al. Trade-Induced Atmospheric Mercury Deposition over China and Implications for Demand-Side Controls. Environ. Sci. Technol. 2018, 52, 2036-2045. [CrossRef]

30. Liang, S.; Wang, H.; Qu, S.; Feng, T.; Guan, D.; Fang, H.; Xu, M. Socioeconomic Drivers of Greenhouse Gas Emissions in the United States. Environ. Sci. Technol. 2016, 50, 7535-7545. [CrossRef]

31. Zhao, X.; Yang, H.; Yang, Z.; Chen, B.; Qin, Y. Applying the input-output method to account for water footprint and virtual water trade in the Haihe River basin in China. Environ. Sci. Technol. 2010, 44, 9150-9156. [CrossRef]

32. Meng, J.; Mi, Z.; Yang, H.; Shan, Y.; Guan, D.; Liu, J. The consumption-based black carbon emissions of China's megacities. J. Clean. Prod. 2017, 161, 1275-1282. [CrossRef]

33. General Office of the State Council. Opinions on Promoting the Revitalization of Dairy Industry to Ensure the Quality and Safety of Dairy Products [WWW Document]. 2018. Available online: http: //www.gov.cn/zhengce/content/2018-06/11/content_5297839.htm (accessed on 6 November 2018).

34. Leontief, W.W. The Structure of American Economy, 1919-1939: An Empirical Application of Equilibrium Analysis; Oxford University Press: Oxford, UK, 1951. 
35. Chen, S.; Chen, B. Network environ perspective for urban metabolism and carbon emissions: A case study of Vienna, Austria. Environ. Sci. Technol. 2012, 46, 4498-4506. [CrossRef]

36. Leontief, W. Structure of the world economy. Am. Econ. Rev. 1974, 64, 823-834. [CrossRef]

37. Chen, S.; Chen, B. Tracking Inter-Regional Carbon Flows: A Hybrid Network Model. Environ. Sci. Technol. 2016, 50, 4731-4741. [CrossRef]

38. Chen, S.; Chen, B. Changing Urban Carbon Metabolism over Time: Historical Trajectory and Future Pathway. Environ. Sci. Technol. 2017, 51,7560-7571. [CrossRef]

39. Yang, S.; Fath, B.; Chen, B. Ecological network analysis of embodied particulate matter 2.5-A case study of Beijing. Appl. Energy 2016, 184, 882-888. [CrossRef]

40. Pan, C.; Peters, G.P.; Andrew, R.M.; Korsbakken, J.I.; Li, S.; Zhou, P.; Zhou, D. Structural Changes in Provincial Emission Transfers within China. Environ. Sci. Technol. 2018, 52, 12958-12967. [CrossRef]

41. Tan, X.; Tong, D.; Huang, Y.; Zhang, Q.; Yan, Y.; Chen, L.; Liu, M.; Hu, Y.; Lin, J.; Streets, D.; et al. Socioeconomic and atmospheric factors affecting aerosol radiative forcing: Production-based versus consumption-based perspective. Atmos. Environ. 2018, 200, 197-207. [CrossRef]

42. National Bureau of Statistics of China. China Statistical Yearbook 2008-2016; China Statistics Press: Beijing, China, 2016.

(C) 2020 by the authors. Licensee MDPI, Basel, Switzerland. This article is an open access article distributed under the terms and conditions of the Creative Commons Attribution (CC BY) license (http://creativecommons.org/licenses/by/4.0/). 